\title{
Dialogue, radiation measurements and other collaborative practices by experts and residents in the former evacuation areas of Fukushima: A case study in Yamakiya District, Kawamata Town ${ }^{\text {मे }}$
}

\author{
T. Yasutaka ${ }^{1, *}$, Y. Kanai ${ }^{1}$, M. Kurihara ${ }^{1}$, T. Kobayashi ${ }^{2}$, A. Kondoh ${ }^{3}$, T. Takahashi ${ }^{2}$ and Y. Kuroda ${ }^{4}$ \\ ${ }^{1}$ National Institute of Advanced Science and Technology (AIST), 1-1-1 Higashi Tsukuba, Ibaraki 305-8567, Japan. \\ 2 Chiba University, Graduate School of Horticulture, 648 Matsudo Matsudo-City, Chiba 271-8510, Japan. \\ ${ }^{3}$ Chiba University, Center for Environmental Remote Sensing, Chiba University, 1-33 Yayoi-cho, Inage-ku, Chiba-City, Cbiba 263-8522, \\ Japan. \\ 4 Research Department, Fukushima Prefectural Centre for Environmental Creation, 2-10 Fukasaku, Miharu-machi, Tamura-gun, \\ Fukushima 963-7700, Japan.
}

Received: 9 June 2020 / Accepted: 9 July 2020

\begin{abstract}
This paper describes the involvement of the residents of the Yamakiya district of the Kawamata town, a former evacuation area after the accident of Fukushima Daiichi Nuclear Power Plant (FDNPP), in the on-going research activities of the authors on the behaviour of radioactive caesium in the environment. By relying on dialogue, measuring radiation, and other collaborative practices, this involvement enabled a series of actions to be taken to resolve the challenges related to the recovery after the lifting of the evacuation order that were appreciated by the residents. The paper also discusses the effects of the interactive program led by the Yamakiya School organized by the authors in cooperation with the residents including among others lectures, voluntary works and radiological surveys on local issues. Based on the above, the authors make recommendations on the desirable form of relationship between residents and experts after an event of large-scale environmental pollution including radiological contamination. Through these activities the authors have also gradually changed their research approach.
\end{abstract}

Keywords: radio-caesium / environmental contamination / environmental monitoring / nuclear power accident / evacuation zone

\section{Introduction}

The Fukushima Daiichi Nuclear Power Plant (FDNPP) accident caused radioactive contamination over a wide area in the Fukushima Prefecture. An evacuation order was issued in the high contamination areas and almost 88000 people were moved. Decontamination started in 2012 and was completed in 2018. It covered residential land, roads, agricultural land, and forest in the range of $20 \mathrm{~m}$ from living areas, except for some areas classified as "difficult to return". Currently, the removed soil and waste are being transported to interim storage facilities. In addition, the evacuation orders were gradually lifted in the accident zone to prepare for the return of the

\footnotetext{
is Note: Parts of Sections 2 and 5 by Naito and Yasutaka were edited and translated into English with permission from the publisher (Naito and Yasutaka, 2019).

*Corresponding author: t.yasutaka@aist.go.jp
}

residents. As of March 2020, evacuation orders have been lifted in all the areas other than the "difficult-to-return" areas. It is to note that the return rate of evacuees after the lifting of the evacuation orders is higher in areas where the evacuation orders were lifted earlier. For example, in the Tamura City where the evacuation orders were lifted in April 2014, the return rate is about $70 \%$ when it is only around $21 \%$ in the village of Iitate and $25 \%$ in the Yamakiya district where the evacuation orders were only lifted in March 2017.

Results of a personal dosimeter (D-shuttle) survey conducted in 2019 on 239 participants in 10 municipalities where the evacuation orders were lifted showed an average annual external radiation effective dose of $0.93 \mathrm{mSv}$, including the natural external exposure, indicating a low level of exposure (Nomura et al., 2020). The low return rate of the population is not only because of radiation concerns, but also because of the long length of the evacuation leading to the establishment of new lives by the evacuees, especially among the younger generation. Children got used to their new schools 


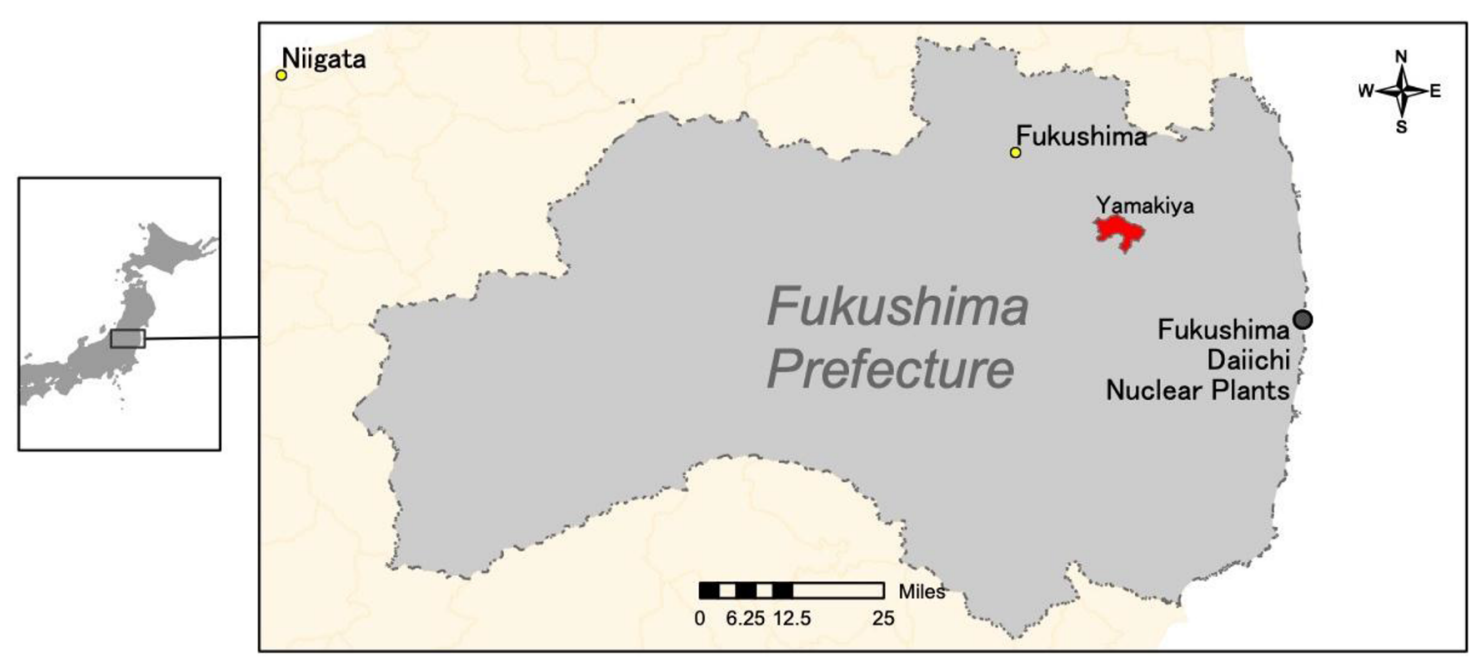

Fig. 1. The location of the Yamakiya distinct.

at the evacuation shelters and young people found employment in the re-settlement areas (Reconstruction Agency, 2016). As a result, in the areas where evacuation orders were lifted late, the proportion of people aged 60 and over increased significantly when compared to before evacuation, resulting in a dramatically declining birth rate and an aging of the population (The Kahoku Shimpo, 2019). Furthermore, after the evacuees returned home, issues in the local community such as the abandonment of agricultural land, the decrease in the number and the aging of resident's association members, and the increase in the distance between occupied adjacent houses were evidenced. In addition, issues occurred in the maintenance of infrastructure such as commercial facilities for shopping, clinics, and agricultural facilities.

Involvement of local stakeholders living in the contaminated areas is important for the management of the recovery phase of the accident and radiological protection experts play a key role to initiate and accompany this involvement (Schneider et al., 2019). In each region, from before returning home, some residents cooperated with various researchers to conduct environmental surveys on radioactive materials to help address issues on the actual situation of radioactive contamination in the living sphere of the area. However, many of these surveys were fragmentary and have not been reported and evaluated.

This paper describes the involvement process of local stakeholders in the authors' ongoing research activities on the behaviour of radioactive caesium in the environment in the Yamakiya district of Kawamata town in the Fukushima Prefecture, a rural area located in the Abukuma Highlands. It also presents the effects of the "Yamakiya School" activities: an interactive learning based on active exchanges between the residents and participants outside the region to understand the changing needs of the residents before and after returning. Finally the paper attempts to illustrate the process of cooperation between experts, professionals and local stakeholders - the so-called "co-expertise process" - which aims to help people living in affected areas to understand the radiological situation they face daily in order to make informed decisions to protect themselves and their loved ones.

\section{Environmental surveys and dialogue in the Yamakiya district of Kawamata}

The Yamakiya district of the Kawamata town, is located approximately $40 \mathrm{~km}$ in the northwest of the FDNPP (Figs. 1 and 2). In April 2011, only the Yamakiya district was designated as a "planned evacuation" area in the Kawamata town and it was evacuated. It is notable that, unlike the neighbouring Iitate village, only a part of Kawamata town was designated as an area to be evacuated. Yamakiya distinct had a population of 1252 before the 2011 accident. The evacuation order was lifted on March 31, 2017, and as of January 1, 2019, 330 people had returned, most of them being elderly (Kawamata Town, 2019). The elementary and junior high schools were reopened in 2017, but the elementary school closed in 2018 owing to a lack of students.

The main industries of Yamakiya district include those of flower and rice cultivation. Cultivation of the flowers Eustoma (Fig. 3) was widely practiced before the accident. Cultivation trials started in 2013 when the evacuation order was lifted, and full-scale shipments re-started from 2014. There was almost no damage to the reputation of the product and shipments resumed at the same level as before the accident. Radioactive contamination of the rice was also tested before the order to lift the evacuation was given and the results were found to comply with the marketing criteria. Full-scale shipments of chrysanthemums and vegetables were also resumed. In addition, the cultivation of the plants Anthurium (Fig. 4) was newly started, a local specialty, resumed through a collaboration project between Kinki University and Kawamata town. Although the traditional production activities were actively resumed, they have not returned to the levels before the accident.

From 2012, the general environmental monitoring of the radiological local situation and specific surveys were conducted in collaboration with members of the local agricultural promotion association and various farmers, and the results were discussed together about once or twice a year. In the last seven years, public concerns and the approach of experts have changed. In the early stages of evacuation, a one way communication toward residents was taken by the experts 

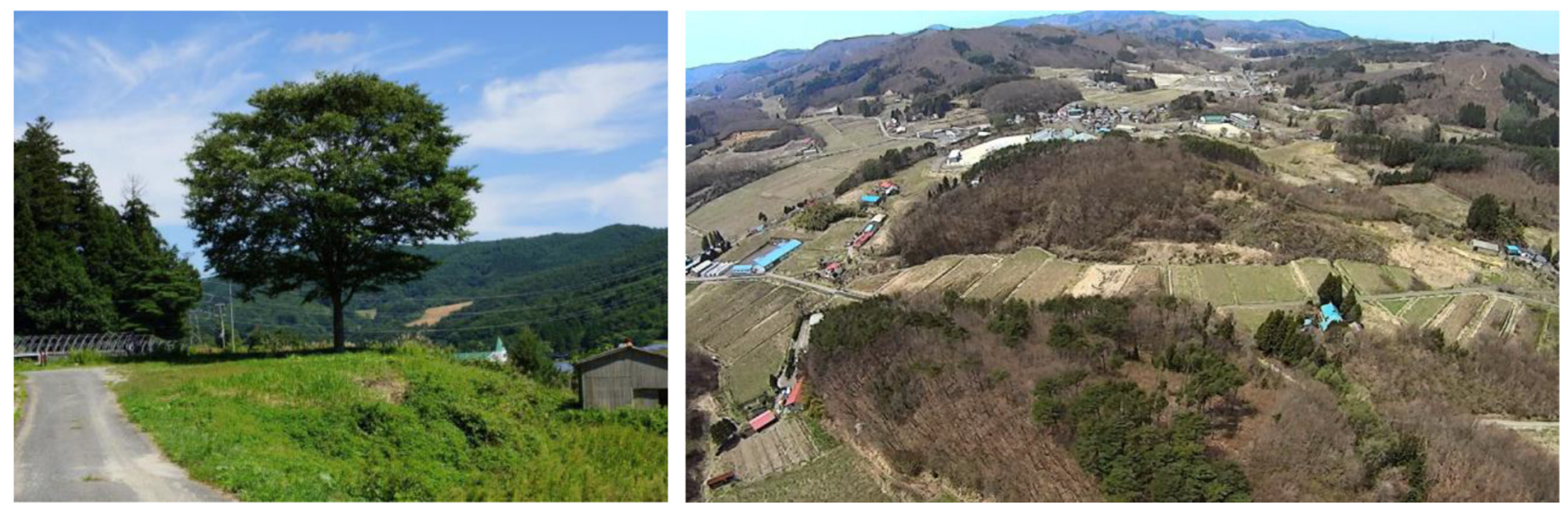

Fig. 2. General view of the Yamikiya distinct.
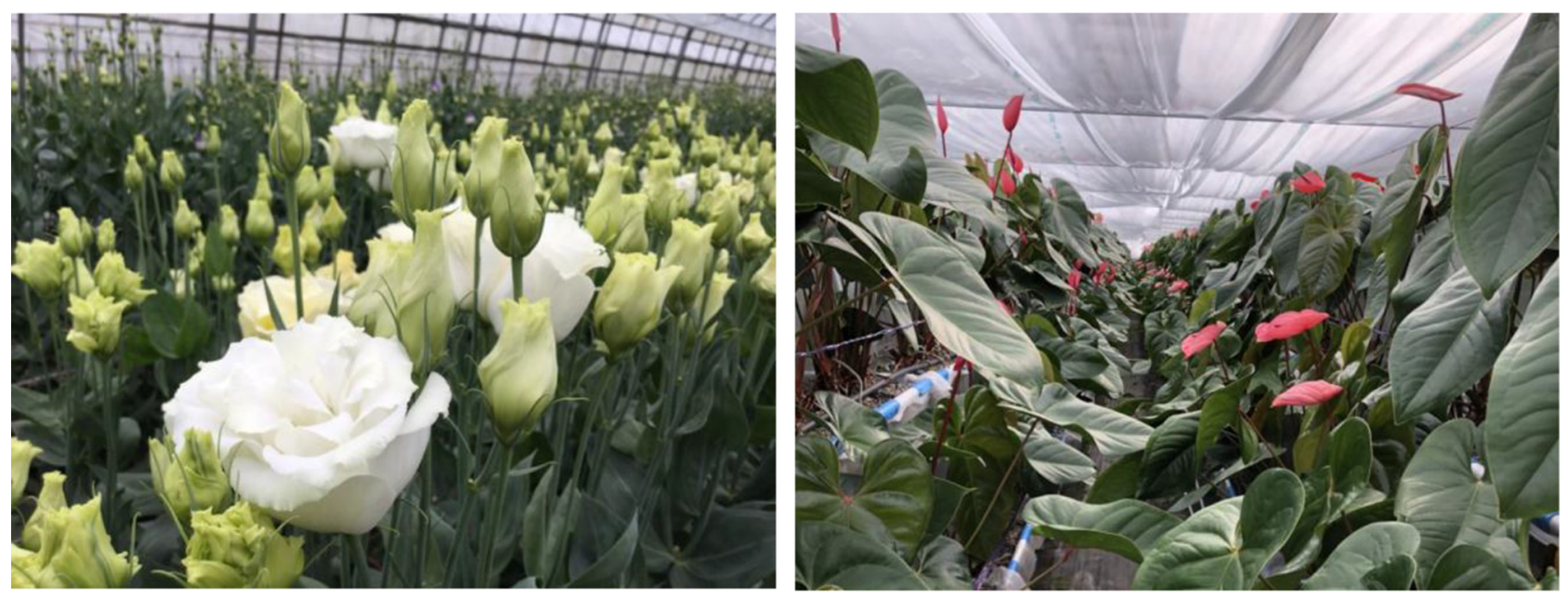

Fig. 3. Cultivation of Eustoma and Anthurium in Yamikiya distinct.

focused on radiation issues (Fig. 4). From the middle to the late stage of the evacuation, a shift was made toward a more interactive approach, but it is only when the evacuation order was lifted that a true interactive approach was developed on the daily-life-related concerns of the residents in addition to those related to the presence of radiation (Fig. 4). The following sections describe the evolution of this process and the main factors that influenced it.

\subsection{The approach before the evacuation order was lifted}

Before the evacuation order was lifted a series of environmental studies were conducted in the Yamakiya district mainly on the measurement and behaviour of ${ }^{137} \mathrm{Cs}$ in water (Tsuji et al., 2014), soil and forests (Takada et al., 2016; Kurihara et al., 2018a, 2018b).

During this first phase, the studies were carried out on the sole initiative of the researchers, and their results were reported in briefing sessions. There was a gap in communication between the researchers' academic reports and presentations and the residents' desire to be informed. The approach was one-way, from the experts to the residents, and the topics of the

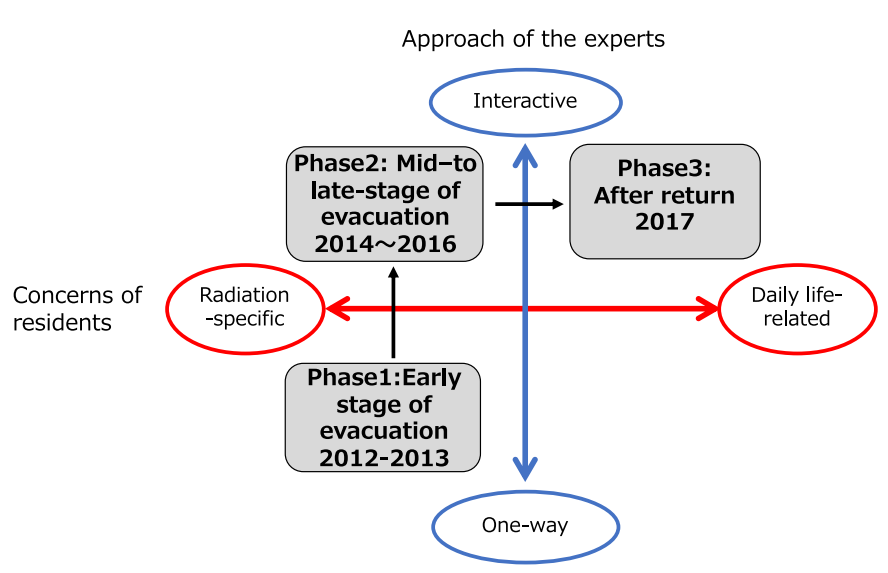

Fig. 4. Changes in the concerns of participating residents in the Yamakiya district and in the approaches of the experts.

studies were focused on radiation. As a result, there were few questions from the residents and sometimes some of them slept during the briefing sessions.

In order to improve this situation, the resident requests concerning the results of the studies collected during surveys 
or individual interviews were gradually integrated into the process. During this second phase, although the study themes remained specific to radioactivity, a two-way communication approach was established through a dialogue between the experts and the residents.

To illustrate this dialogue here are some of the questions asked by residents regarding ${ }^{137} \mathrm{Cs}$ in water.

(1) "In most national monitoring surveys of 137Cs in water, the lower limit of detection is around $1 \mathrm{BqL} \mathrm{L}^{-1}$. As a result, almost all data are below this limit. But what is the actual concentration level? I would like to know the concentration of $137 \mathrm{Cs}$ in groundwater from the newly installed wells".

(2) "The topsoil of rice fields is to be decontaminated. Will the rice field be contaminated again by irrigation water used when rice cultivation is resumed?".

(3) "Only a part of the forest is to be decontaminated. However, is 137Cs not flowing out of the mountain forests through stream water?".

In order to response to these questions, a series of measurements campaign were initiated. The concentration in ${ }^{137} \mathrm{Cs}$ was measured in different wells. Results showed extremely low concentrations $\left(0.0003-0.0005 \mathrm{BqL}^{-1}\right)$. Dissolved ${ }^{137} \mathrm{Cs}$ (in a form easily absorbed by plants) was also measured at eight locations in the rivers of Yamakiya district between 2013 and 2015. Here again results showed extremely low concentrations (between $0.003-0.06 \mathrm{BqL}^{-1}$ ) with a confirmed tendency to gradually decrease. Based on the measurement results of dissolved ${ }^{137} \mathrm{Cs}$ and suspended ${ }^{137} \mathrm{Cs}$ in river and stream water and the amount of water generally used in the rice fields it was estimated that the contribution of irrigation water, when cultivation of rice fields is resumed after decontamination, was very small (Nakamura and Yasutaka, 2012; Tsuji et al., 2014). Furthermore, monitoring results at the outlet of the small watershed toward Yamakiya indicated that the concentration of suspended ${ }^{137} \mathrm{Cs}$ increased during heavy rainfall due to sediment runoff, but it is a temporary phenomenon, and the amount of ${ }^{137} \mathrm{Cs}$ released was estimated at $0.1-0.3 \%$ annually with respect to the amount of deposition in the area (Nakamura and Yasutaka, 2012).

These results were shared and discussed with the residents of Yamakiya district to improve their understanding of the local radiological situation. The researchers' efforts to answer the questions were appreciated by the residents. During the dialogues, the residents expressed their satisfaction. So they mentioned among other comments that "researchers measure the concentration of water according to our needs, which allows us to know the situation we are facing" or that "Some researchers send us their articles once their work is finished, but do not come to give us explanations. And then one day we see them on TV talking about their results!". "Sharing research results with us face to face before publishing them leads to a feeling of trust".

By adapting to the residents' questions, the research brought results closer to their daily life. By sharing these results directly the confidence in the figures also in those who produced them has increased accordingly. The dialogue is a basis for the co-expertise process.

\subsection{The approach after the lifting of the evacuation order}

Discussion in the issues raised by residents became increasingly rich and serious as the lifting of the evacuation order was getting closer, and a change in their interests and concerns emerged. Before the evacuation order was lifted, attention was mainly focused on le levels of radioactivity, in air, water, and soil. After the evacuation order was lifted, concerns related to daily life became more prevalent. The questions related to the restrictions of activities in nondecontaminated forests in particular concerning the gathering of mushrooms and wild vegetables or those related to the levels of radioactivity in the various crops became more and more frequent. Residents' concern over negative rumours regarding the radiological quality of agricultural products also raised. In addition to the aspects linked to the presence of radioactivity in the environment, after the residents' return there was an increased interest in social and economic issues, in particular those related to the resumption of agriculture, the rehabilitation of infrastructures and the maintenance of local communities. Past experience had shown that after natural disasters when residents return from a prolonged evacuation, social and economic problems are at the heart of people's concerns (Hashimoto et al., 2013). Thus, reduction of the population and its aging due to the low number of active people among the returnees as well as the problems related to the management of agricultural facilities and agricultural land due to a decrease in the number of farmers and the lack of labour became frequently issues raised in the dialogue meetings.

In the third phase, research related to radiation was conducted taking into account these changes in the interest of residents. Thus, studies have been carried out on the contamination of wild vegetables and other forest products, on the effects of the presence of contaminated forests in the vicinity of living areas, and also on the individual doses received by residents during their daily activities. The implementation of these studies, in which the residents were closely associated, made it possible to deepen the exchanges between experts and residents and to progressively develop among them a practical culture of radiological protection.

\section{The Yamakiya School interactive learning and exchange program}

Considering that in the past, the Yamakiya district had a good experience in welcoming people from urban areas for field trainings, the authors after consulting with volunteers from the district, launched the "Yamakiya School". This interactive learning and exchange program for local and other district residents aims to strengthen the ties within the local community, to find solutions to overcome the lack of local resources and to encourage the resumption of agriculture. The program includes activities promoting the discovery of the district and also the support of local agriculture. These activities make it possible to initiate a dialogue between the local residents, the visitors from other districts and the experts not only on questions relating to the radiological situation but also to all aspects of living in the district and other places. 


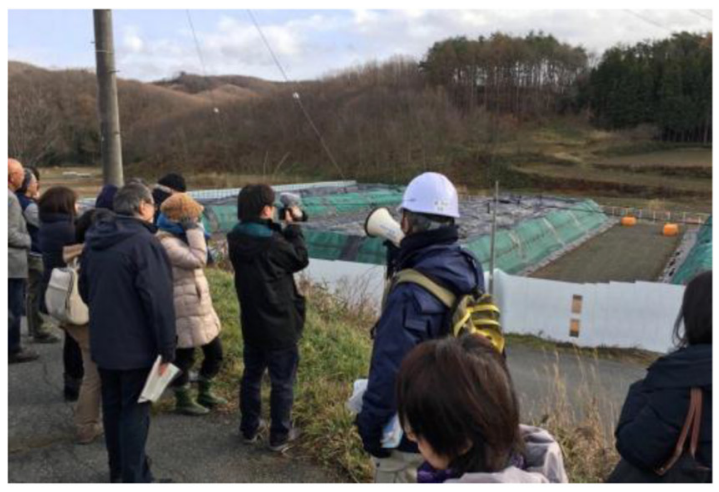

(a)

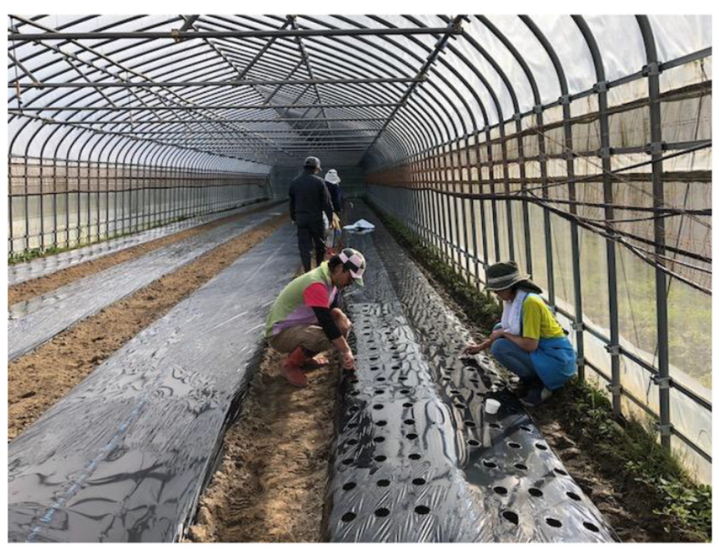

(c)

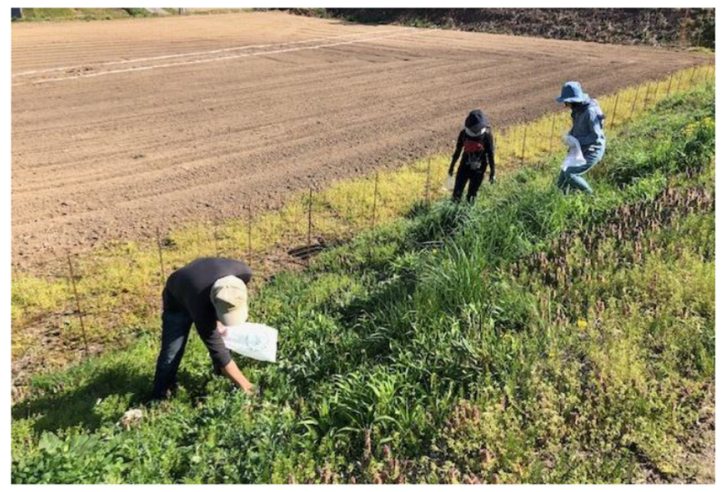

(b)

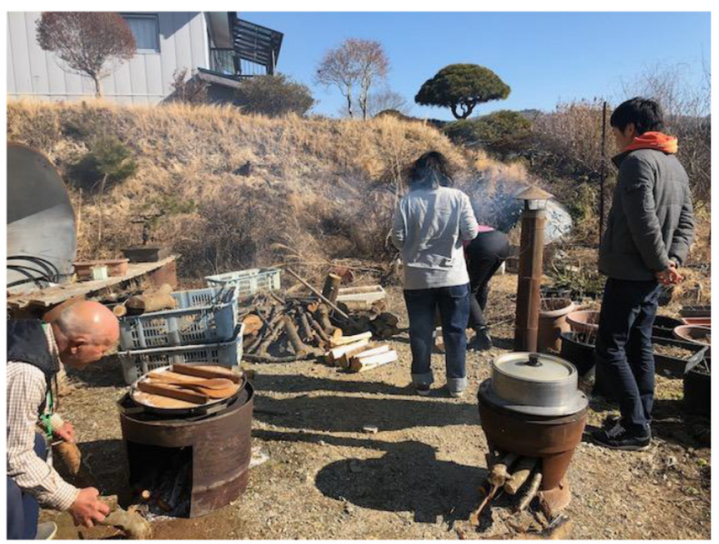

(d)

Fig. 5. (a)Visit of a temporally storage site of the decontamination waste in Yamakiya; (b) Gathering the wild plant with residents and visitors; (c) Work on farms growing Eustoma with visitors; (d) Making miso activity.

\subsection{Yamakiya School activity details}

The "Yamikiya School" was launched in March 2015 by the local residents and the researchers. The program has been conducted 29 times with the participation of over 500 researchers, students, and residents of the Yamakiya district but also from all of Fukushima prefecture and other prefectures. It operated without interruptions until 2019. The "School" carried out numerous activities including farm work and dialogue, exchange meetings, tours of the Yamakiya district and field surveys (Fig. 5). Table 1 presents an overview of the activities carried out each year.

Work on farms growing vegetables or flowers, such as Eustoma and Dahlia, were carried out by participants on a voluntary basis. This work was followed by dialogues between participants and the farmers on the local challenges of agriculture. The exchange meetings included lectures by experts on the situation in Yamakiya after the accident, the levels of contamination by ${ }^{137} \mathrm{Cs}$ in the district or the removal of soil and the management of the radioactive waste. On the occasion of these meetings the participants could taste the local specialties. During the district visits, participants were able to attend local socio-cultural activities, visit the local shrines and also the border of the "difficult-to-return" area. The surveys carried out included sampling wild vegetables and mushrooms and measuring their ${ }^{137} \mathrm{Cs}$ concentration. Other activities such as flower arrangement using Eustoma and making the traditional food miso were also conducted. During each of these activities, dialogues between the Yamikiya residents and the participants were encouraged in order to develop mutual understanding and continued interaction.

\subsection{Characteristics of the participants}

Figure 6 shows the number and attributes of participants at the Yamakiya School by year, excluding residents. The number of participants is based on registration records and is approximate as partial participation was also encouraged.

Figure 6 shows that the number of participants increased each year. Researchers and students accounted for more than $80 \%$ of the total from 2015 to 2017 . They were initially from fields related to the environmental dynamics of radioactive materials, such as pedology, ecology, hydrology and environmental radioactivity. Through networking, researchers from various fields such as architecture, civil engineering, agriculture, and psychology became progressively involved. Furthermore, cooperation with social science researchers was promoted to meet the diversifying needs of the residents of the Yamakiya district. However, the number of researchers 
Table 1. Activities of the Yamakiya School (multiple contents are included in a single event).

\begin{tabular}{llllll}
\hline Year activity details & 2015 & 2016 & 2017 & 2018 & 2019 \\
\hline Farm work and dialogue & 1 & 7 & 8 & 7 & 5 \\
Exchange meetings & 1 & 7 & 6 & 5 & 3 \\
Lectures and seminars & 1 & 5 & 2 & 0 & 2 \\
Local tours & 1 & 5 & 5 & 2 & 2 \\
Surveys & 0 & 0 & 0 & 2 & 2 \\
Others & 0 & 1 & 4 & 3 & 3 \\
Number of "schools" in the year & 1 & 7 & 8 & 7 & 6 \\
Number or the participants & 14 & 88 & 130 & 136 & 154 \\
\hline
\end{tabular}

after 2017 declined because environmental radiation research gradually subsided. Meanwhile, the number of residents from the Fukushima Prefecture and outside increased to $40 \%$ in 2019. This may be because the evacuation order was lifted in March 2017, which reduced concerns about radiation among residents and the spread of information from participants to friends and acquaintances and an increase in the number of repeating visitors.

Figure 7 shows the number of times residents in the Yamakiya district participated in the program. Fifteen residents (about $5 \%$ of returnees) have participated, but of those six people have participated five times or more confirming that some residents were more actively involved.

\section{Effectiveness of the Yamakiya School}

\subsection{Interview method}

After the evacuation order was lifted in March 2017, returning residents resumed farming, including Eustoma and rice, and festivals at the shrine resumed for the first time in seven years, but many issues remain in the Yamakiya district, as well as areas that were evacuated around the same time. In terms of the radiological situation, the anxiety about the effects of radiation, the use of the non-decontaminated forests, the methods of using former temporary storage sites for the waste are very present concerns for the residents. In terms of society and economy, the low return rate to Yamakiya, which is about $30 \%$, led to the high aging society, the shortage of farmers and manpower, the reduction of joint work as for example the cleaning of the irrigation canals, the dilution of local communities (relationships between neighbours tend to be sparser than before) and the maintenance of social infrastructure such as grocery stores, restaurants, public halls, and clinics. A survey was conducted in March and April 2020 on four residents who had returned to the Yamakiya district and who had frequently participated in the School. Oral and written explanations about the participation in the survey were given to them and their consents were obtained. Interviews were conducted through telephone or E-mail because of the COVID-19 pandemic.

\subsection{Effect of the Yamakiya School program on the community}

Table 2 presents the main issues of the Yamakiya district, examples of activities at the School and in research, and the

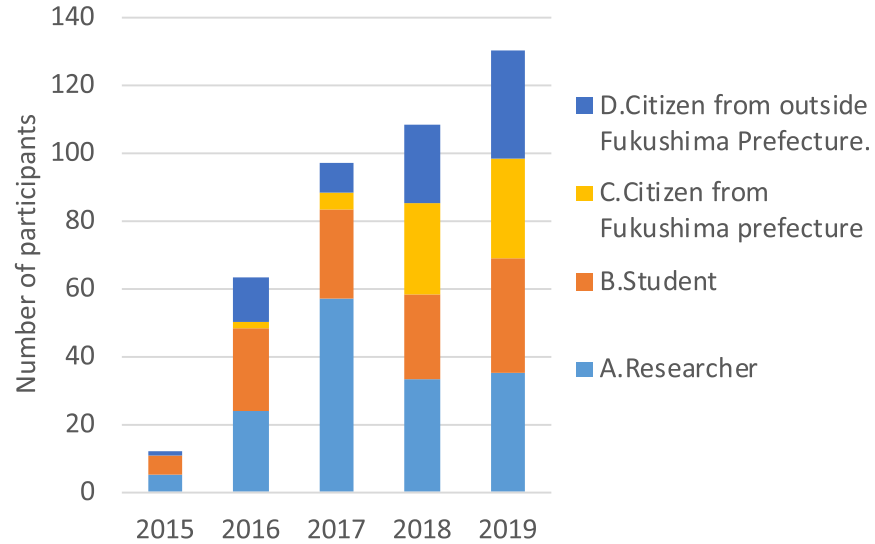

Fig. 6. Number and quality of the participants at the Yamakiya School coming from outside Yamakiya by year.

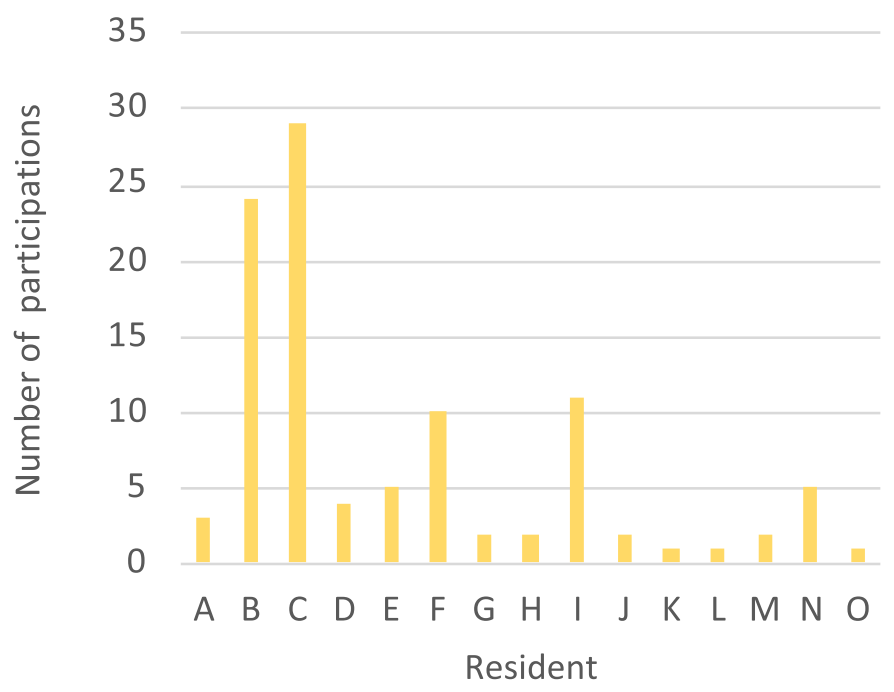

Fig. 7. Number of participations at the Yamakiya School by the residents of the Yamakiya district.

contents of the interviews with residents who participated in the survey. Based on these results, we tried to ascertain the effects of the School on local issues.

The first issue deals with radiation effects.

As part of the Yamakiya School activities, Caesium 137 was measured in the environment (water, soil, forests, etc.) as well as in the crops and forest products and the results were shared with the residents. In addition, the School prepared meals with foods whose safety was confirmed and which was eaten together with the participants. Residents indicated the importance of measuring radiation according to their needs and providing face-to-face the results in return. They suggested that eating the radiation-measured foods together with the researchers increased their sense of security. It is also interesting to note that students, researchers, and residents from outside, including children, visiting Yamakiya through the School, gave the residents confidence in terms of safety.

The second issue is the division of local communities and the reduction of local resources. 
Table 2. Residents' views on the effects of the Yamakiya School on local issues.

\begin{tabular}{lll}
\hline Local issue & $\begin{array}{l}\text { Example of Yamakiya } \\
\text { School and research } \\
\text { activities }\end{array}$ & $\begin{array}{l}\text { Details of interviews with Yamakiya residents } \\
\text { participating in Yamakiya School }\end{array}$
\end{tabular}

Issue (1):

- Radiation effects

- Environmental safety

- Safety of crops and forest products

- Reputation

Issue (2):

- Divided local communities and reduced local resources

- Disruption of cultural traditions

- Maintenance and management

of the local infrastructure

- Deterioration of the landscape
- Measurement of ${ }^{137} \mathrm{Cs}$

concentration in water

- External exposure dose

- Evaluation of behaviour

of ${ }^{137} \mathrm{Cs}$ in forests

- Agricultural work and

crop surveys

- Wild vegetable surveys

- Sharing of survey results

- Lectures on radioactive

materials

- Eat wild vegetables

together after measuring

their concentration of

${ }^{137} \mathrm{Cs}$

- Tours of Yamakiya

- Events utilizing local

specialties (flower

arrangement, miso-making,

etc.)

- Exchange events for residents of Yamakiya and elsewhere using local ingredients

- Agricultural experiences
Issue (3):

- Resuming agriculture

- Insufficient manpower

- Introduction of new crops and technologies

- Animal damage

- Decreased production motivation
- Volunteering in agriculture (about one day per month)

- Tea parties
- It was significant that the university brought in students. The students probably also had concerns about whether the location was safe. If students can be reassured about safety, then we (residents) can also feel safe. Students do their research and report to the teacher.

- I am confident that it is really safe because the researchers brought their children.

- We and the participants can feel safe by collecting and measuring agricultural products and wild vegetables, and based on the results eat them together.

- These exchanges can be made and awareness shared by having fun together. Yamakiya is believed to be high in radioactive material, but in small individual steps, we have gradually gained confidence.

-I think that the School contributes to the community. I think that it contributes economically because it buys ingredients.

- The things people from elsewhere notice helps us reconfirm the appeal of Yamakiya that we take for granted.

- Speaking with people from outside the area allows you to get various new information. For example, when discussing dried daikon, we talk about how delicious the daikon in Marumori is, and how the dried daikon in Nagasaki is. This makes us think about what we could do in Yamakiya. Although we will not make money right away, we might want to imitate them or try a different approach.

- Yamakiya people who do not participate are still very cautious and critical about the outside world. I want such people to participate.

- Events such as the School may be temporary, but if we continue to nurture connections, we may find something of value.

- Some local people have given up or lost motivation; I think it would be good to let the locals know what is happening at the School.

- We want to share the idea of making the whole area a place where people want to come to and feel comfortable. I want to share this intention, but it is difficult.

- The areas along the national road are managed, but places that are not convenient and rough have reverted to nature. Even if they are to revert to nature, it would be good to manage the whole area as a landscape.

- Agricultural volunteers were effective to some extent in the early stage of resuming agriculture. However, once full-scale agriculture was resumed, agricultural volunteers who came about once a month had no significant effect.

- Training people from urban areas and students from outside Yamakiya in farm work is troublesome and 
Table 2. (continued).

\begin{tabular}{lll}
\hline Local issue & $\begin{array}{l}\text { Example of Yamakiya } \\
\text { School and research } \\
\text { activities }\end{array}$ & $\begin{array}{l}\text { Details of interviews with Yamakiya residents } \\
\text { participating in Yamakiya School }\end{array}$ \\
\hline & $\begin{array}{l}\text { can reduce work efficiency, but having them getting } \\
\text { to know Yamakiya and working together is } \\
\text { stimulating, and therefore, attractive. } \\
\text { - We are thinking of creating a volunteer system by } \\
\text { expanding the network from the School. I think we } \\
\text { need a system, such as recruitment, giving vegetables } \\
\text { as an expression of gratitude, or the like. } \\
\text { There are limits to compensation and assistance, so } \\
\text { we must consider what we can do to continue. Both } \\
\text { product and tourism resource perspectives are needed. }\end{array}$ \\
\end{tabular}

The rapidly declining birth rate and the aging of the population, the disruption of cultural traditions, the division within the community, the decline in maintenance and management of the local infrastructure, and the deterioration of the landscape due to the presence of waste bags of the decontamination, are realities that residents are confronted with and which are of great concern to them. To address these issues, the School conducted activities such as volunteers' participation in farming, meetings on utilizing local specialty products (flower arrangement, miso-making, etc.), exchange meetings between the Yamakiya residents and the visitors using local ingredients, and tours for traditional performing arts at local festivals. Participants to the survey indicated that the benefits of these activities included rediscovering the good aspects of living in Yamakiya through the feedback of the visiting participants, contribution of participants' voluntary work to the local economy, and obtaining information about the situation in other affected communities thanks to the numerous exchanges with people from other areas through new networks. Although, these activities were considered beneficial, nevertheless the interviewees highlighted the difficulty to reach out the non-participating residents of Yamakiya and to disseminate the experience of the School outside.

Although the regularly increase in the number of outside participants does not resolve at all the question of the depopulation of the community, the interviewees underlined that their continued participation, especially from young people, increased the sense of security and confidence of the residents. They however mentioned that these positive effects do not spread to the whole region because of the low participation of residents perceived as mainly due to the advanced age of the population who returned.

Regarding the third issue of the lack of manpower and the decline in motivation to resume agriculture in the district, the School organized work on the farm with volunteers followed by tea parties to promote dialogue between local farmers and participants after volunteering activities. The interviewees confirmed that volunteers are an important source of manpower in the early stages of resuming agriculture, but volunteering one day per month after agriculture is fully resumed does not make much of an impact. The residents suggested that the exchange through agricultural volunteering

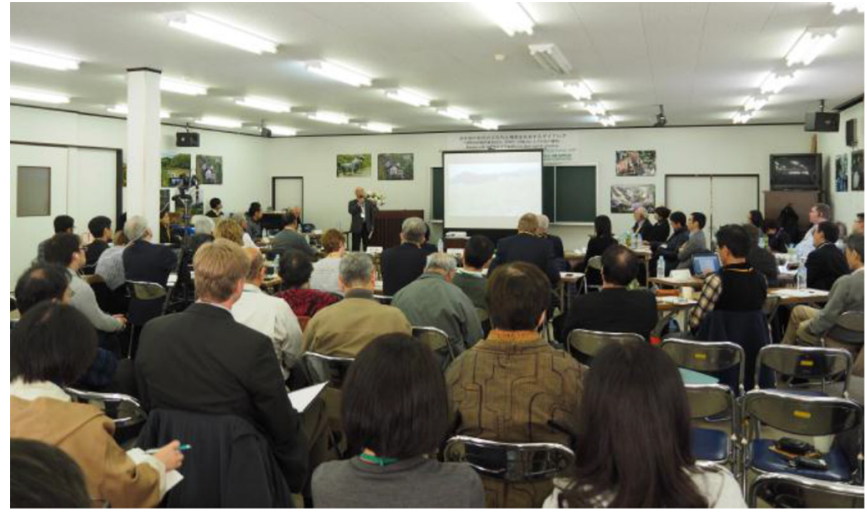

Fig. 8. The Fukushima Dialogue in Yamakiya district in November 2017.

has increased their motivation in terms of production activities but also for improving their living conditions.

\section{The Fukushima Dialogue in Yamakiya}

As part of its general activities, the Yamakiya school organized a Dialogue meeting on 25 and 26 November 2017 in the framework of the cooperation with the International Commission on Radiological Protection (Lochard et al., 2019) entitled "Dialogue with residents of Yamakiya to share current situations". The participants in the dialogue, including several foreign experts, were welcomed by the mayor of the city of Kawamata who on this occasion presented the problems of the region and met with the participants. On the first day, the participants visited a temple, a flower production farm, one of the decontamination waste storage sites located in the district, as well as a farmer who chose to return to Yamakiya after the lifting of the evacuation order. They also shared a meal prepared with local products. The second day took place in the form of a seminar. In the morning a series of presentations on the history and culture in Yamakiya, the restart of the agriculture in the area, the testimonies of several farmers, and the management of the radioactive waste from the soil decontamination, allowed participants to better understand the challenges faced by the residents. In the afternoon, a panel 
discussion on the theme of sharing the current situation and its problems and the future of Yamakiya allowed a small group of residents to share their experience and express their concerns and expectations (Ethos in Fukushima, 2018) (Fig. 8).

The Yamakiya dialogue meeting was a catalyst for new developments and prospects in the district by starting some citizen-led projects involving local residents and former residents of Futaba Town located in the "difficult-to-return" area.

One project was the transplantation of flowers from Futaba Town to Yamakiya, with the support of the government which organized the radiation measurements of the soil and the flowers and their transport. This project, which gave rise to articles in the media marked greatly the participants because of its symbolic dimension (The Kahoku Shimpo, 2018).

As the lesson after Chernobyl already suggested, the "direct involvement of residents and authorities and professionals" is a key factor for the rehabilitation of the living conditions in the affected areas after a nuclear accident. This involvement implies the "shifting from a centralized, topdown, prescriptive and normative approach to a more decentralized bottom up, and quality-driven approach" (Lochard, 2013). Despite the fact that many issues remain in the Yamakiya district, the School experience feedback has established the possibility of the birth of a new form of cooperation between the residents, the experts, and the authorities, which is promising for the future of the region.

\section{Conclusion}

Residents' collective learning and assessment of the local situation with appropriate help of experts allow passing from a fuzzy and negative appreciation of the radiological situation to more contrasted and reliable picture (Lochard, 2013). Environmental research and interactive learning and exchange programs in the affected areas implemented with the cooperation of local residents of Yamakiya district help in resolving environmental issues related to the presence of the radioactivity in their daily life, provide a sense of security for residents, and lead to a vision for the future. Researchers and their activities must take into account the questions and concerns of the affected people and should involve them in their work. They must utilize research results to help residents and society and contribute to improve their living conditions. As shown in the results of the interviews, studies with only academic interest and without providing appropriate feedback to the community result in distrust by residents. Contrarily, practical collaborative research between the researchers and residents closely linked to the local problems the residents are facing contributes in the residents regaining a sense of control over their lives.

In addition, the local knowledge of the residents is often essential for researcher to interpret their measurement results and carry out their studies. Experience has shown that this knowledge has often proven to be very useful in solving difficult questions. The independent involvement of stakeholders, such as local residents and authorities is key to solving the local challenges related to the consequences of the accident. As described in the concept of the Partnership of Sustainable Development Goals, dialogue is needed for the continued involvement of experts in boosting the efforts of the residents (United Nation, 2020). Close collaboration between researchers and residents will continue to be important for future studies in the affected area at the service of improving the situation.

The needs and concerns of the residents with respect to their daily lives changed when the evacuation order was lifted. The role of experts also changed to respond to the interests of the residents. As the level of exposure is progressively decreasing, the researchers in the Yamakiya district has to adapt and to focus on the fields of interest described in this article. It is important to build a flexible system in which researchers and specialists in various fields can respond to changes in the needs and concerns of residents. In order to achieve this, building a network with comprehensive cooperation between research institutes, universities, and specific regions is crucial. Drawing on past experience in implementing the co-expertise process, the authors have modified their practices step by step, favouring dialogue with locals to share the results of their research (Rollinger et al., 2016).

The authors would now like to deepen their understanding on the current state of radiation exposure in the disasteraffected areas and to work with the residents and local governments in accumulating scientific knowledge to contribute to the reconstruction of these areas and to improve the living conditions of the residents.

\section{Acknowledgements}

We thank the Genkatsu Kanno, Genei Kannno, Shoko Kannno, Katsuhisa Hirono, Kuniko Hirono, Akihiko Hirono, Asao Kanno, Kinichi Ouchi, Gouki Taniguchi, Katsunobu Honda, Koichi Shigihara and authorities of Kawamata and local residents of Yamakiya for their assistance during our field survey and all activity. This study was partly supported by JSPS KAKENHI (Grant numbers 26241023 and 18H04141).

\section{References}

Ethos in Fukushima. 2018. November 2017 The Materials of Yamakiya Dialogue Seminar. In: Dialogue with residents of Yamakiya to share current situations-Continuing the dialogue in cooperation with the International Commission on Radiological Protection (ICRP), November 25-26, 2017, Yamakiya, Kawamata Town, Fukushima, Retrieved from http://ethos-fukushima.blog spot.com/2018/01/201711252625-26-november-2017-materials. html (Accessed on 12 April 2020).

Hashimoto S, Arita H, Yasutaka T, Iwasaki Y. 2013. Potential Impacts of prolonged evacuation due to radioactive contamination on the reconstruction of rural Fukushima (in Japanese). Irrig Drain Rural Eng $J$ 81: 153-162

Kawamata Town. 2019. Resident population in Kawamata Town (2019) Yamakiya District (in Japanese). Retrieved from http:// www.town.kawamata.lg.jp/site/sinsai-saigai/yamakiyatikukyo jyuujyoukyou.html (Accessed: January 10 2020).

Kurihara M, et al. 2018a. Spatial and temporal variation in vertical migration of dissolved 137Cs passed through the litter layer in Fukushima forests. J Environ Radioact 192: 1-9. 
Kurihara M, et al. 2018b. Radiocesium migration in the litter layer of different forest types in Fukushima, Japan. $J$ Environ Radioact 187: 81-19.

Lochard J. 2013. Stakeholder engagement in regaining decent living conditions after Chernobyl. In: Social and Ethical Aspects of Radiation Risk Management (D. Oughton, S.O. Hansson, Eds); pp. 311-332. Elsevier Science.

Lochard J, Schneider T, Ando R, Niwa O, Clement C, Lecomte JF, Tada JI. 2019. An overview of the dialogue meetings initiated by ICRP in Japan after the Fukushima accident. Radioprotection 54 (2): 87-101. Available from https://www.radioprotection.org/ articles/radiopro/full_html/2019/02/radiopro190031/radio pro190031.html.

Naito W, Yasutaka T. 2019. Measuring and communicating radiation levels in Fukushima: Pragmatic collaborative research with local residents (in Japanese). JJapan Secur Water Environ 42(A3): 88-92.

Nakamura K, Yasutaka T. 2012. Concentration of radiocesium in stream water from a mountainous catchment area during rainfall events. In: International Symposium on Environmental monitoring and dose estimation of residents after accident of TEPCO's Fukushima Daiichi Nuclear Power Station, 14 December 2012, The Shiran Hall, Kyoto University.

Nomura S, et al. 2020. Low dose of external exposure among returnees to former evacuation areas: a cross-sectional allmunicipality joint study following the 2011 Fukushima Daiichi nuclear power plant incident. J Radiol Protect 40: 1-18.

Reconstruction Agency. 2016. Overall Report of the Survey on the Intentions of the Residents of the Evacuation Ordered Zones, etc. due to the Nuclear Disaster in Fukushima Prefecture in Fiscal Year 2016 (in Japanese). Retrieved from https://www.reconstruction. go.jp/topics/main-cat1/sub-cat1-4/ikoucyousa/28ikouchousakek ka_zentai.pdf (Accessed on 12 April 2020).

Rollinger F, Lochard J, Schneider T. 2016. Involving stakeholders in radiological protection decision making: Recovery history and lessons from the people of Fukushima. In: Proceedings of the International Workshop on the Fukushima Dialogue Initiative. Ann. ICRP 45(2S): 99-104.

Schneider T, Maître1 M, Lochard J, Charron S, Lecomte JF, Ando R, Kanai Y, Kurihara M, Kuroda Y, Miyazaki M, Naito W, Orita M, Takamura N, Tanigawa K, Tsubokura M, Yasutaka T. 2019. The role of radiological protection experts in stakeholder involvement in the recovery phase of post-nuclear accident situations: Some lessons from the Fukushima-Daïchi NPP accident. Radioprotection 54(4): 259-270.

Takada M, Tetsuo Y, Toshinori O. 2016. Simplified measurement method for dissolved radio-Cs in litter and soil seepage water using copper-substituted Prussian blue. Chemosphere 163(2016): 234-241.

The Kahoku Shimpo. 2018. "For the flower garden that heals people", Futaba's cluster amaryllis, bulbs transplanted to Yamakiya where the evacuation order was lifted (in Japanese). Kahoku Shinpo Online News, Published on 17 April 2014, Retrieved from https:// www.kahoku.co.jp/tohokunews/201804/20180417_63047.html (Accessed on 12 April 2020).

The Kahoku Shimpo. 2019. Residence rate in 9 evacuation zones in Fukushima remains at $23.2 \%$, and the rate of the aging population is high (in Japanese). Retrieved from https://www.kahoku.co.jp/ tohokunews/201904/20190412 63016.html (Accessed on 12 April 2020).

Tsuji H, Yasutaka T, Kawabe Y, Onishi T, Komai T. 2014. Distribution of dissolved and particulate radiocesium concentrations along rivers and the relations between radiocesium concentration and deposition after the nuclear power plant accident in Fukushima. Water Res. 60: 15-27.

United Nation. 2020. Goal 17: Revitalize the global partnership for sustainable development. Available from https://sdgs.un.org/ goals/goal17.

Cite this article as: Yasutaka T, Kanai Y, Kurihara M, Kobayashi T, Kondoh A, Takahashi T, Kuroda Y. 2020. Dialogue, radiation measurements and other collaborative practices by experts and residents in the former evacuation areas of Fukushima: A case study in Yamakiya District, Kawamata Town. Radioprotection 55(3): 215-224 